DOE/ER/40751-4

\title{
LIQUID HELIUM FLUID DYNAMICS STUDIES
}

\author{
Final Report
}

for the Period June 1, 1992 - May 31, 1996

\author{
S. W. Van Sciver \\ Principal Investigator \\ Florida State University \\ National High Magnetic Field Laboratory \\ 1800 E. Paul Dirac Drive \\ Tallahassee, FL 32310
}

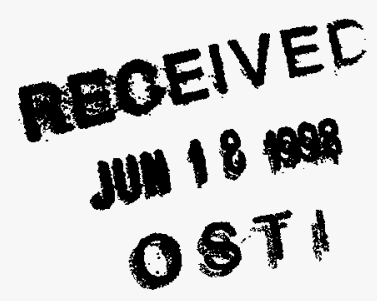

August 1, 1996

DISTRIBUTION OF THIS DOCUMENT IS UNIMMTED

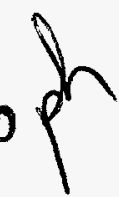

MASTER

\author{
Prepared for
}

THE U.S. DEPARTMENT OF ENERGY

AGREEMENT NO. DE-AC05-92ER40751 


\section{DISCLAIMER}

This report was prepared as an account of work sponsored by an agency of the United States Government. Neither the United States Government nor any agency thereof, nor any of their employees, makes any warranty, express or implied, or assumes any legal liability or responsibility for the accuracy, completeness, or usefulness of any information, apparatus, product, or process disclosed, or represents that its use would not infringe privately owned rights. Reference herein to any specific commercial product, process, or service by trade name, trademark, manufacturer, or otherwise does not necessarily constitute or imply its endorsement, recommendation, or favoring by the United States Government or any agency thereof. The views and opinions of authors expressed herein do not necessarily state or reflect those of the United States Government or any agency thereof. 


\section{DISCLAIMER}

Portions of this document may be illegible electronic image products. Images are produced from the best available original document. 


\section{NOTICE}

This report was prepared as an account of work sponsored by the United States Government. Neither the United States nor the Department of Energy, nor any of their employees, nor any of their contractors, subcontractors, or their employees, makes any warranty, expressed or implied, or assumes any legal liability or responsibility for the accuracy, completeness or usefulness of any information, apparatus, product or process disclosed or represents that its use would not infringe privately-owned rights. 


\section{Liquid Helium Fluid Dynamics Studies \\ S.W. Van Sciver, P.I. \\ Florida State University \\ National High Magnetic Field Laboratory}

\section{Summary}

The present report pertains to work carried out over the grant period June 1, 1992 to May 31, 1996) under the support of the US Department of EnergyDivision of High Energy Physics. The report is divided into categories according to the 1992 grant statement of work.

\section{Two Phase Flow Studies}

During the previous grant period, we successfully completed a two-phase flow study involving low temperature helium. To accomplish this task, we constructed a large scale horizontal experimental two-phase flow test apparatus consisting of a vertical bellows cryostat and a five meter long horizontal flow loop. Tests conducted with this new apparatus included: pressure drop and void fraction measurements of two-phase helium flowing in horizontal tubes under various conditions and an investigation into the performance of a venturi flowmeter in horizontal flows.

The two-phase helium pressure drop measurements were carried out on two inline test sections: one with a length of $1.28 \mathrm{~m}$ and ID of $5.3 \mathrm{~mm}$, and the other with length of $0.76 \mathrm{~m}$ and ID of $4.6 \mathrm{~mm}$. Data for pressure drop and void fraction were obtained at mass flowrates from $0.5 \mathrm{~g} / \mathrm{s}$ to $2.0 \mathrm{~g} / \mathrm{s}$ and under system pressures between $0.65 \mathrm{~atm}$ and $1.2 \mathrm{~atm}$. In this study, the effects of mass flux, vapor quality, system pressure, and tube size on the two-phase friction multiplier and void fraction were investigated.

Results for the two-phase pressure drop measurements were analyzed in terms of the conventional two-phase frictional multiplier, which is a function of system pressure and vapor quality. Mass flow rate does not appear to have a significant effect on the two-phase frictional multiplier. In general, the homogeneous model gives a much better prediction of the friction multiplier than the LockhartMartinelli correlation as illustrated in Fig. 1. Results of this study have been published in Cryogenics (see Ref. 5).

The performance of a venturi flow meter in two-phase helium flow was also investigated by installing two identical venturis, with $2.3 \mathrm{~mm}$ throat and $4.6 \mathrm{~mm}$ inlet diameter, in the same flow loop. With one operating in single phase liquid helium and one in two-phase helium, the ratio of the pressure drop across the two venturis was found to be well correlated with vapor quality in the flow. Comparison of such a correlation with homogeneous model predictions shows 
good agreement especially at vapor qualities below about 0.6, as shown in Fig.2. This work has already been published (Refs. 2 and 6).

For the remainder of the current grant period, our effort will be focused on an experimental investigation of heat transfer to two-phase helium flow. Localized heat transfer is being measured in forced up-flow and down-flow two-phase helium. Quantities to be determined include: heat transfer coefficient in the nucleate boiling and film boiling regime, peak and recovery heat fluxes both as they depend on system parameters such as temperature, flow rate and test section dimensions. Preliminary results indicate that the critical heat fluxes and film boiling heat transfer coefficients depend on flow rate and flow direction, relative to the gravitational acceleration. This latter result suggests a contribution due to natural circulation. This study is the subject of a paper presented at the 1995 Cryogenic Engineering Conference (Ref. 8).

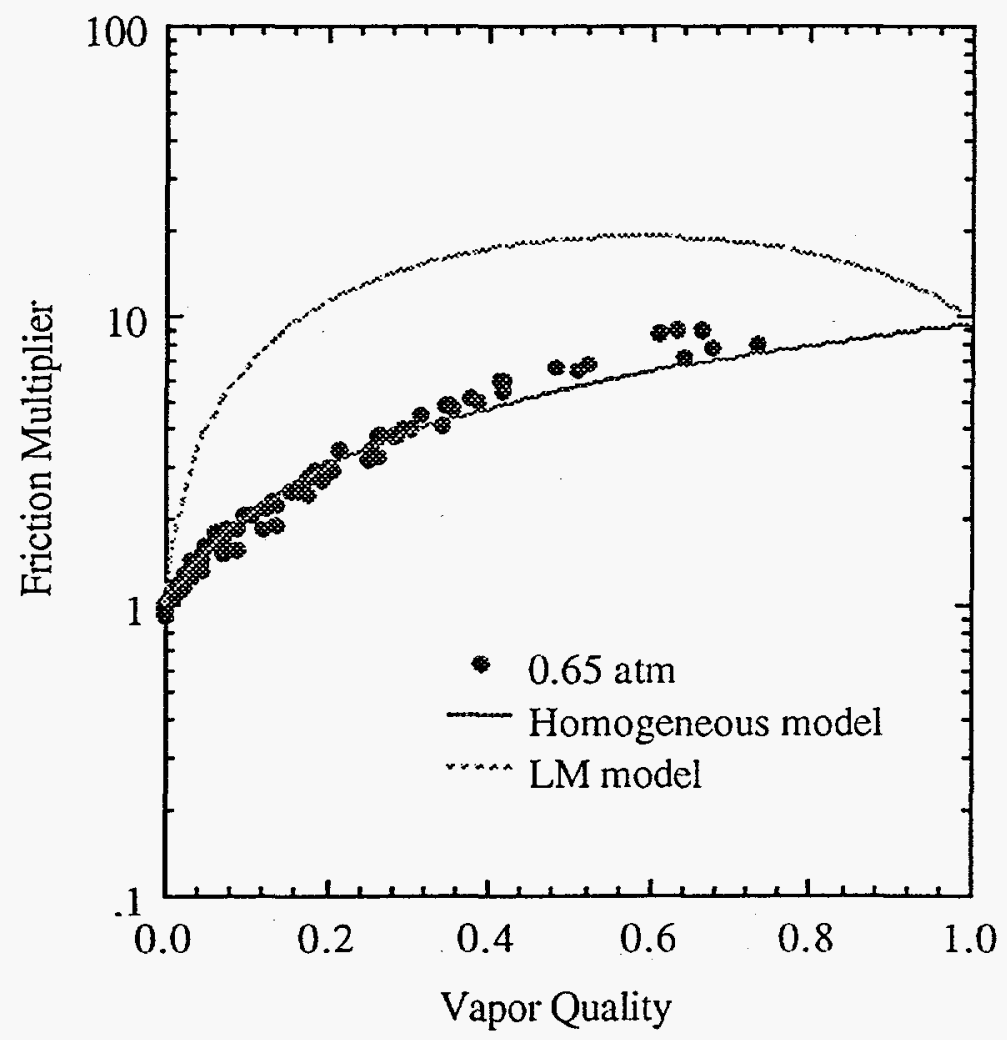

Figure 1: Comparison between the measured friction multipliers and the predictions from the homogeneous model and the Lockhart-Martinelli correlation at $0.65 \mathrm{~atm}$. 


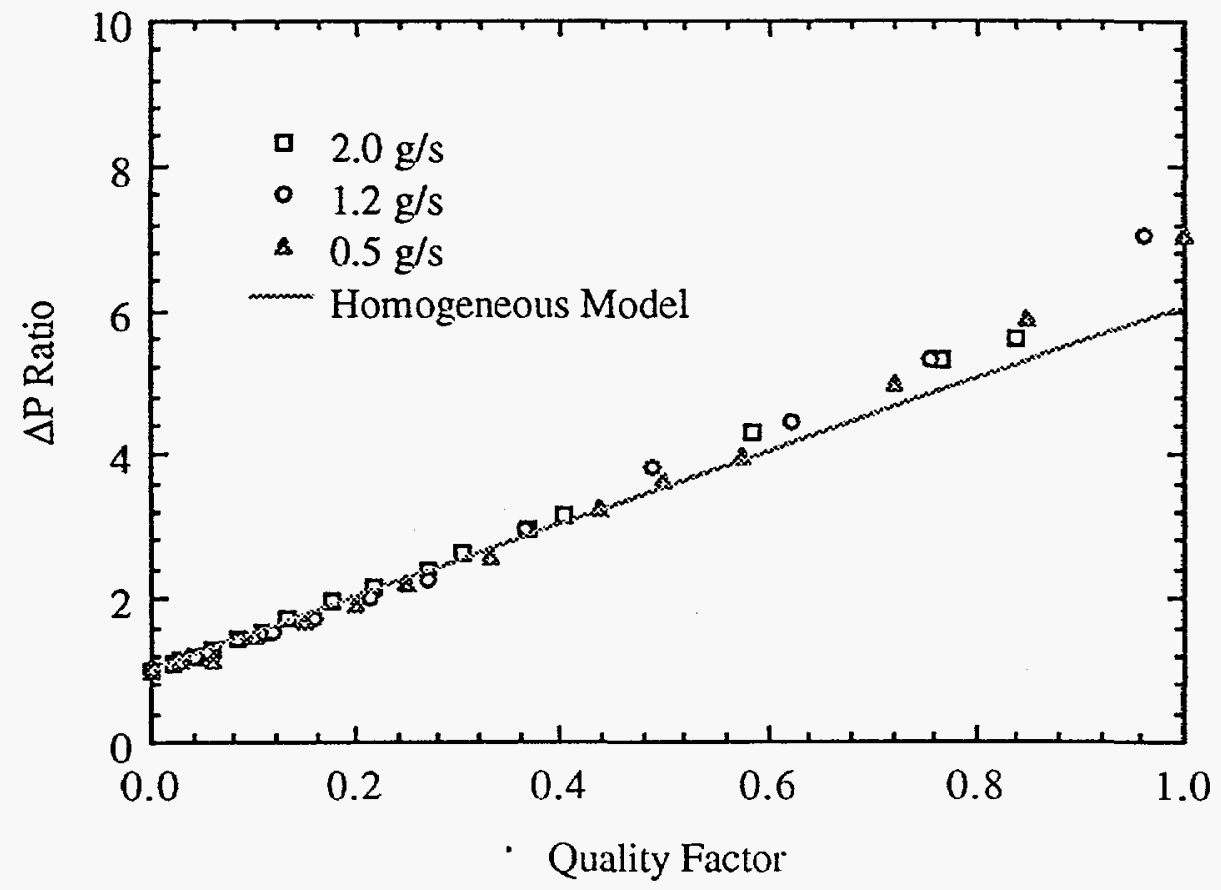

Figure 2: Ratio of pressure drop across two venturis at 1.2 bar.

\section{Transient Heat Transfer Studies}

Over the past grant period, we also conducted a study of transient heat transfer in a partially confined volume (channel $25.4 \mathrm{~mm}$ long, $1.65 \mathrm{~mm}$ wide) of helium at $4.2 \mathrm{~K}$. The experiment used thin-film, patterned Rh-Fe sensors mounted on an alumina substrate (obtained from Lake Shore Cryotronics) as a combined heater/temperature sensor. One sensor served as both a pulse heater and thermometer, providing microsecond response; while a slightly smaller sensor was mounted directly opposite on the upper surface to monitor the temperature at various gap spacing. Rectangular heat pulses were sufficiently long (up to 30 s) to observe the evolution of steady-state conditions for power densities of 2.0 $\mathrm{W} / \mathrm{cm}^{2}$ or less. A central concern was to determine whether sensor heating is confined to the thin-film resistive traces at the lowest powers.

Comparison of our results with those of earlier workers suggests that at low powers (producing temperature differences of less than $1 \mathrm{~K}$ at atmospheric pressure) nucleate boiling is confined to the helium adjacent to the thin-film traces. For sufficiently large powers (producing temperature differences of several kelvin), steady-state results indicate film boiling helium over the whole sensor surface. Intermediate-power step inputs (in the $0.15-0.60 \mathrm{~W} / \mathrm{cm}^{2}$ range, referred to the whole sensor face area) yield unstable traces, typically one or two large temperature excursions followed by continuing fluctuations. We conjecture that a vapor film covers the thin-film areas at these powers, which 
repeatedly spills over onto the adjacent (cooler) alumina surface, where it is cooled and retreats. Such a cooling effect occurring at the onset of film boiling may explain why the temperature "takeoff" (at higher powers) is generally less pronounced than in the traces of earlier workers. Under steady-state conditions, the fluctuations observed at intermediate powers result in an effective heat transfer greater than that of a uniformly heated surface.

Comparison of heater and passive sensor temperature traces in a $0.4 \mathrm{~mm}$ gap channel indicates that stable nucleate boiling on the heater surface corresponds to liquid on the passive surface, and film boiling on the heater surface to film boiling on the passive surface. Large excursions and steady-state fluctuations in the heater temperature (at intermediate powers) educe corresponding (loweramplitude) behavior on the passive surface (Fig. 3). The elapsed time between start of heating and start of passive sensor temperature rise is on the order of the time in which the energy input is sufficient to produce a column of helium vapor in the space between the two sensors.

Data were also taken at pressures ranging up to 3.0 bar. These traces show how the dependence of temperature difference on pressure can change between early (liquid still present) and steady-state times. Temperature excursions are smaller at higher pressures, probably due to larger heat capacity per unit volume.

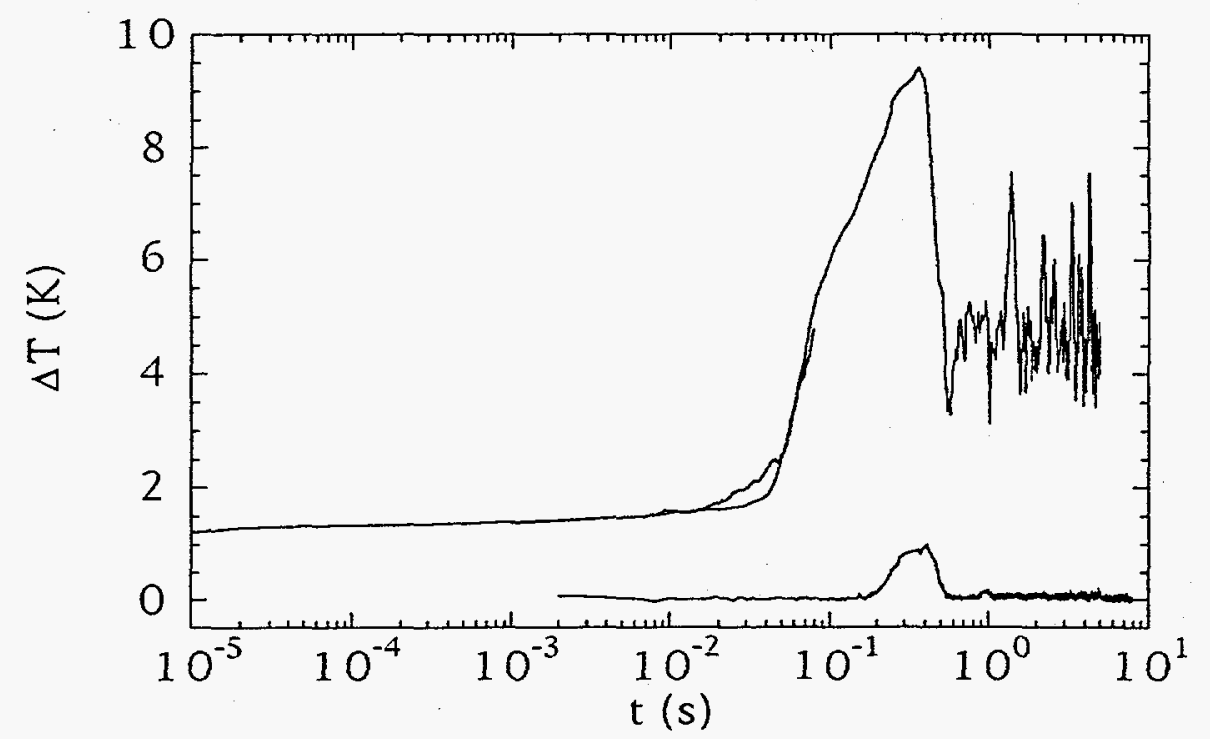

Figure 3. Heater (upper) and passive sensor temperature traces show response to a $0.25 \mathrm{~W} / \mathrm{cm}^{2}$ pulse at 1.0 bar. Channel gap is $0.4 \mathrm{~mm}$.

As Schmidt observed in a closed-volume study (Cryogenics 28:585 (1988)), one effect of increased pressure is a reduction in film boiling takeoff times. But unlike Schmidt, we found that greater confinement produced only a small (instead of 
significant) reduction in these characteristic times. We conjecture that Schmidt observed larger reductions because of a large pressure rise that accompanied heat pulses in his completely closed volume. Reports on this project have been published (Ref. 3 and 7).

\section{Related Research Activities}

\section{Co- and Counter-current He II Heat Exchangers}

We recently completed a study of He II heat exchangers for forced flow application. This project, which was initiated under DoE/HEP funding, was completed under support from the National Science Foundation.

The model heat exchanger consisted of a straight rectangular copper bar with two channels milled on the two opposite sides so that the cross-section looks like the letter " $\mathrm{H}$ ". Two rectangular thin-wall brass tubes each with one wide side machined off were soldered into the base copper channels. This design ensured an accurate measure of the heat transfer area and reduced the amount of heat transferred through the extended surfaces. The design also benefits from both solder and brass having very low thermal conductivities compared to copper. The heat exchanger was instrumented with 18 Allen Bradley carbon resistance thermometers, nine on each channel to measure the He II fluid temperature profiles. The results were presented in the form of temperatures over the length of heat exchanger.

The measured temperatures in both parallel and counterflow He II heat exchangers were compared with a numerical model based on the He II energy equation. The numerical model used to fit experimental results has one adjustable parameter, the overall heat transfer coefficient $h_{0}$. The best fit value for $h_{0}$ in our experiment is $4700 \mathrm{~W} / \mathrm{m}^{2} \mathrm{~K}$ and independent of the mass flow rate, which corresponds to a Kapitza conductance of about $4000 \mathrm{~W} / \mathrm{m}^{2} \mathrm{~K}$ at $1.8 \mathrm{~K}$. This result confirms our previous finding that $h_{O}$ is not dependent on fluid velocity (J.G. Weisend I and S. W. Van Sciver, Proceedings 5th AIAA/ASME Thermophysical and Heat Transfer Conference, June 18-20, 1990, ASME Publication H00587). The heat transfer coefficient, $h_{0}$, in forced-flow He II heat exchanger is dominated by the Kapitza conductance between the He II and solid surface. This work resulted in a Ph.D. thesis and a review article on this project is in preparation. 
He II Heat Transport in Cylindrical Geometry

This project received partial support from our DoE/HEP grant. The principal purpose of the study was to understand the heat transfer mechanisms that apply to He II confined to a cylindrical geometry, such as might occur in a strand of superconductor wire in a bath of He II. The question which we wanted to answer was: Does the Gorter-Mellink heat transport mechanism for He II apply when there is a large gradient in the heat flux and a corresponding gradient in the voracity. Preliminary studies had suggested that additional terms to the GM equation may be necessary to accurately model the heat transport.

Heat transfer induced temperature difference measurements were obtained for three different radii cylinders, $1.6,2.4$ and $4.8 \mathrm{~mm}$, and at different radial positions in the fluid adjacent to the heater. A thermocouple-SQUID temperature difference measuring system was developed specifically for this project. The measurements were compared to theory for linear heat transport generalized to cylindrical geometry. The predicted radial functional dependence was found to correspond to the data, however, the absolute value deviated. These deviations appeared to scale with heater radius. This work resulted in one Ph.D. thesis and a publication is in preparation.

\section{Publications}

1. S. W. Van Sciver, "He II Cooling of Large Superconducting Magnet Systems", Cryogenics Vol. 32 Supplement, 320, 1992 (Invited paper at the 14th International Cryogenic Engineering Conference, June 8-12, $1992 \mathrm{Kiev}$, Ukraine.)

2. X. Huang and S.W. Van Sciver, An Investigation into the Performance of a Venturi in Two-Phase Helium Flow, Adv. Cryo. Engn. Vol. 39A, 1065 (1994).

3. Kingsburg and S. W. Van Sciver, Transient Heat Transfer in Liquid and Supercritical Helium, Adv. Cryo. Engn. Vol. 39A, 1631 (1994).

4. S.W. Van Sciver, Recent Advances in Helium Heat and Mass Transfer, HD267, ed. J.P. Kelley and J. Goodman HTD-Vol. 267, 1993 (ASME Winter Annual Meeting, November, 1993) pp. 1-11

5. X. Huang and S.W. Van Sciver, "Pressure Drop and Void Fraction of Twophase Helium Flowing in Horizontal Tubes", Cryogenics Vol. 35, 467(1995), attached.

6. X. Huang and S.W. Van Sciver, "The Performance of a Venturi Flow Meter in Two-phase Helium Flow" Cryogenics Vol. 36, 303 (1996), attached. 
7. D. L. Kingsbury and S.W. Van Sciver, "Transient Heat Transfer in a Channel of Liquid or Supercritical Helium" Cryogenics Vol. 35, 573 (1995), attached.

8. J. Panek, X. Huang and S.W. Van Sciver, "Localized Heat Transfer to Vertical Forced Flow Two-phase Helium" Advances in Cryogenic Engineering Vol. 41 (to be published)

9. X. Huang, J. Panek and S.W. Van Sciver "Heat and Mass Transfer between Two Saturated He II Baths", Proceedings ICEC16/ICMC, May 20-25, 1996 Kitakushu, Japan, Elsevier (to be published), copy attached

\section{PhD Theses}

1. X. Huang, Hydrodynamic Study of Two-Phase Helium Flow, Ph.D. Thesis, Nuclear Engineering and Engineering Physics Department, University of Wisconsin-Madison (1994), abstract attached.

2. D. P. Pearson, He II Heat Transport in Cylindrical Geometry Ph.D. Thesis, Physics Department, University of Wisconsin-Madison (1994). (Partial support from DoE/HEP)

3. Y. Huang, Co and Counterflow He II Heat Exchangers, Ph.D. Thesis, Nuclear Engineering and Engineering Physics Department, University of WisconsinMadison (1994). (Partial support from DoE/HEP) 